\title{
Gestational Age-Dependent Changes in Plasma Inositol Levels and Surfactant Composition in the Fetal Rat
}

\author{
J. EGBERTS AND W. A. NOORT \\ Department of Obstetrics and Gynecology, Leiden University Medical Center, 2300 RC Leiden, The Netherlands
}

\begin{abstract}
To study the possibility that changes in fetal surfactant composition depend on the availability of inositol, we isolated surfactant material from lungs of fetal and neonatal rats and estimated their plasma inositol concentration. During the 18- to 22-day gestational period the amount of surfactant increases from 0.17 to $3.10 \mu \mathrm{mol}$ phospholipids/g wet lung. From day 20 onward, $70 \%$ or more of the phospholipids is phosphatidylcholine. In this period the relatively high percentage of phosphatidylinositol $(8 \%)$ in the lung surfactant decreases to $4 \%$ whereas the percentage of phosphatidylglycerol increases from 2 to $8 \%$ at parturition. During gestation the phospholipid/protein ratio of the surfactant material increase from 3 to 11 and the highest ratio is found immediately after birth. It decreases again $24 \mathrm{~h}$ after birth to values characteristic for surfactant from adult rats. The plasma inositol concentration drops during the 18- to 22-day period from 0.81 to $0.26 \mathrm{mmol} / \mathrm{liter}$ and a similar decrease in inositol concentration occurs in amniotic fluids. The phosphatidylglyercol/ phosphatidylinositol ratio of surfactant correlated negatively with the fetal plasma inositol concentration. It is most likely that the reduction in the level of fetal plasma inositol resulting from a declining production and an increasing metabolism, causes the decrease in phosphatidylinositol and increase in PG content of the surfactant of the fetal rat. (Pediatr Res 20: 24-27, 1986)
\end{abstract}

\section{Abbreviations}

PI, phosphatidylinositol

PG, phosphatidylglycerol

DSPC, disaturated phosphatidyl choline

The production of fetal lung surfactant is initiated during the last period of pregnancy. During its maturation changes occur both in the amount produced and in its phospholipid composition (1).

In the human fetus these compositional changes include: 1) enrichment in phosphatidylcholine and especially saturated phosphatidylcholine $(2,3), 2)$ a temporary increase in the percentage of PI and later on a decrease in its percentage with a concomitant increase in the percentage of PG (4).

In man, $\mathrm{PG}$ is an important minor phospholipid of surfactant and its appearance in amniotic fluid is an indication that the lung will function normally at birth (4).

It has been suggested that in the fetus the percentage of PI and PG changes because of a decrease in fetal plasma inositol con-

Received February 25, 1985; accepted August 15, 1985

Reprint requests Dr. J. Egberts, Department of Obstetrics/Gynecology, Leiden University Medical Center, P.O. Box 9600, 2300 RC Leiden, The Netherlands. centration (5). Both PI and PG have the same precursor (CDPdiacyl-glycerol) and several investigators have shown that in adult rabbits the production of PI and PG depended on changes in the concentration of inositol (6-8). In the fetus, such a relationship has not yet been studied.

The aim of this study was therefore to determine whether compositional changes occur in fetal rat lung surfactant and if these correlate with changes in plasma inositol levels.

\section{MATERIALS AND METHODS}

Animals. Young female Wistar rats $(n=74)$ weighting approximately $175 \mathrm{~g}$ were obtained from CPB.TNO (Zeist, The Netherlands). They were mated for $4 \mathrm{~h}$ once a week and diagnosis of pregnancy was based on increases in body weights and abdominal palpation. The day after mating was called day 1 of gestation.

Material was obtained during the 18- to 22-day period and shortly after birth ( $1 \mathrm{~h}$ and 1 day postpartum). The pregnant rats were anaesthetized with Nembutal and blood was sampled from the vena cava caudalis. Fetuses were delivered by cesarean section and "amniotic fluid" (amniotic fluid contaminated by allantoic fluid) was also collected. Fetal blood was obtained after dissection of the great vessels. The fetal lungs were removed from the thorax and separated from the trachea and the heart. Newborn rats and their does were killed by ether inhalation and blood and lung tissue were obtained as described in the "Results." There were no differences in the amount or composition of surfactant isolated from rats, anaesthetized with Nembutal or does, killed by ether inhalation (Table 1, maternal).

Lung surfactant. At least $0.5 \mathrm{~g}$ of lung tissue from one or a pool of animals from the same litter was minced in 1.1 M sucrose and homogenized in a Potter-Elvehjem tube, equipped with a Teflon pestle (clearance $0.5 \mathrm{~mm}$ ). A sample of the homogenate was retained for determination of the tissue phospholipid composition. The rest was filtered through one layer of Olympus lens paper and a seven-step discontinuous sucrose density gradient (0.8-0.2 M sucrose) was layered on the top of the filtrate (9). Separation was obtained by centrifugation at $140 \times g$ for 15 minutes followed by $45,000 \times g$ for $5 \mathrm{~h}$ in a Beckman $\mathrm{J} 2-21$ High Speed Centrifuge with a fixed angle rotor (type JA 20). We collected an opaque band or in case of " 18 day" material (if hardly anything was visible) the band corresponding with the 0.4 $\mathrm{M}$ sucrose layer and stored the material at $-20^{\circ} \mathrm{C}$ (surfactant fraction). Samples of the surfactant fraction and lung tissue homogenate were extracted with three volumes of chloroform and methanol $(2: 1)$. The chloroform layer was collected and the upper layer was extracted again with two volumes of chloroform. The chloroform layers were combined and evaporated to dryness under nitrogen. The extract of lipids was used for: 1) estimation of the total phospholipid phosphorus content according to the method of Bhagwanani et al. (10). 2) separation of the individual phospholipids by one dimensional thin layer chromatography 
Table 1. Phospholipid composition of surfactant of fetal, newborn, and adult rats (mean \pm SEM)

\begin{tabular}{|c|c|c|c|c|c|c|c|}
\hline & \multicolumn{5}{|c|}{ Fetal age (days) } & Newborn & Maternal \\
\hline \multicolumn{8}{|l|}{ Phospholipid classes (\%) } \\
\hline Sphingomyelin & $4.9 \pm 1.1$ & $7.1 \pm 0.8$ & $4.2 \pm 1.1$ & $1.8 \pm 0.6$ & $1.8 \pm 0.3$ & $1.7 \pm 0.5$ & $2.5 \pm 0.2$ \\
\hline Phosphatidylcholine* & $59.1 \pm 1.4$ & $64.8 \pm 0.8$ & $70.6 \pm 2.0$ & $75.5 \pm 1.2$ & $77.5 \pm 0.9$ & $76.4 \pm 0.7$ & $77.9 \pm 0.4$ \\
\hline Phosphatidylserine & $(62 . \pm 0.5) \dagger$ & $(4.0 \pm 1.0)$ & $(3.9 \pm 0.3)$ & $(2.9 \pm 0.8)$ & $(2.4 \pm 0.8)$ & $(3.0 \pm 0.5)$ & $\mathrm{ND} \ddagger$ \\
\hline PG & $4.0 \pm 1.7$ & $1.5 \pm 0.4$ & $2.7 \pm 0.4$ & $5.8 \pm 0.4$ & $8.3 \pm 0.4$ & $8.1 \pm 0.6$ & $8.4 \pm 0.2$ \\
\hline Unidentified & $5.0 \pm 1.0$ & $3.1 \pm 0.8$ & $2.1 \pm 0.4$ & $2.5 \pm 0.3$ & $2.5 \pm 0.2$ & $2.8 \pm 0.2$ & $2.0 \pm 0.1$ \\
\hline No. of samples & $5(5) \dagger$ & $5(5)$ & $8(3)$ & $7(4)$ & $10(10)$ & $8(8)$ & 46 \\
\hline
\end{tabular}

* Phosphatidylcholine was not always separated from phosphatidylserine and the results present the sum of the percentages of the (PC + PS) spot.

$\dagger$ Percentages of phosphatidylserine of those cases where separation was achieved.

II Not determined.

(HPTLC plate, Merck no. 60 F254), using a solvent of chloroform/ethanol/ $\mathrm{H}_{2} \mathrm{O} /$ triethylamine $(30: 34: 7: 35)$ as described by Touchstone et al. (11).

The phospholipid spots were visualized under UV light after spraying the plate with an aqueous solution of $0.01 \%$ Rhodamine $6 \mathrm{G}$. They were scraped directly into tubes for phosphorus determination.

For the determination of phosphorus/protein ratio, proteins were determined in surfactant fractions according to the BioRad Protein Assay modification of the method of Bradford (12). Bovine serum albumin was used as standard.

Inositol. The inositol concentration in amniotic fluid and in plasma of fetal, newborn and adult (female) rats was determined using the enzymatic procedure as described by Garcia Buñuel and Garcia Buñuel (13). We dialyzed the sample by centrifugation $(800 \times g$ for $90 \mathrm{~min})$ to remove excess of proteins and cleared the dialysate of intrinsic NADH, glucose, and glucose-6phosphate with $\mathrm{HCl}$ and hydroxylamine. The excess of hydroxylamine was destructed by boiling the sample for $10 \mathrm{~min}$.

Inositol dehydrogenase (Sigma), in a stock solution of Tris buffer containing bovine serum albumin, barbital, and NAD (Sigma) is added to the cooled sample and the mixture is incubated at $25^{\circ} \mathrm{C}$ for $30 \mathrm{~min}$. The amount of reaction product: $\mathrm{NADH}$, is measured by fluorometry. We used the difference in fluorescence of samples with and without inositol dehydrogenase to calculate the inositol concentration. All determinations were done in duplicate. Results are presented as mean $\pm \mathrm{SEM}$, and correlation coefficients and regression functions were estimated by using General Statistics of the Hewlett Packard 9825 A software.

\section{RESULTS}

The amount of material, isolated by density gradient centrifugation from fetal, newborn, and adult rats is shown in Figure 1 . On day 18 very low amounts of phospholipid material were found in the $0.4 \mathrm{M}$ sucrose layer $(0.17 \mu \mathrm{mol} / \mathrm{g}$ wet lung $)$ and its composition (Table 1) resembles that of fetal lung tissue homogenate (results not shown).

From day 19 onward, the amount of surfactant in the fetal lung increased significantly (Fig. 1) its composition still resembles that of 18-day material. Thereafter the composition of the socalled surfactant fraction changes significantly and lamellar bodies could be found easily. The percentage of phosphatidylcholine increased and the percentages of sphingomyelin and of phosphatidylethanolamine decreased and the highest percentage of PI (7.4\%) was found in the 20-day surfactant material while the percentages of $P G$ were very low.

Both the amount and the percentage of PG increased from

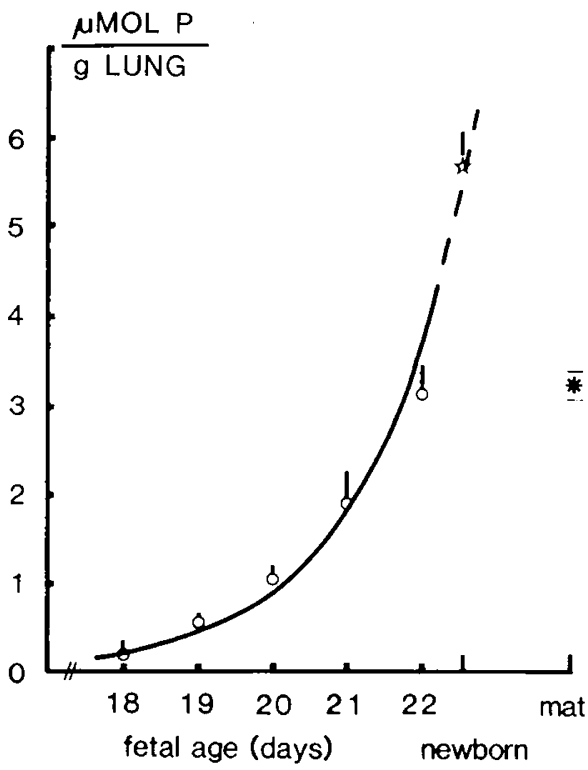

Fig. 1. Changes in the amount of fetal surfactant phospholipids during gestation and first postnatal day compared to the amount of surfactant in the adult rat. The results are the mean $\pm S E$ of five to 10 assays of fetal material and of 46 assays of adult surfactant. Significant increase in the amount of surfactant was seen from day 19 onward $(p<0.005)$.

day 20 onward while the percentage of PI decreased. During that period the phospholipid/protein ratios increased also until after birth (Fig. 2). However, during the first postnatal day the phospholipid/protein ratio decreased again quickly; the values of the 1-h-old animals $(n=4)$ were twice as high as those of the adult rats but those of the 1-day-old newborns $(n=3)$ did not differ from the values of the adult rats.

The plasma inositol concentration of the fetal, newborn, and adult (female) rats is shown in Figure 3 . There was a significant decrease in the fetal inositol levels during gestation $(r=0.878, p$ $<0.001, n=46$ ) and after birth, the inositol concentration was the same as in the adult rats in which the inositol levels did not change during pregnancy.

A significant relationship was found between the fetal plasma inositol levels and the PI/PG ratio of lung tissue $(r=0.863, p<$ $0.001, n=42$ ) and PI/PG ratio of surfactant fraction from day 19 onward ( $r=0.785, p<0.001, n=36$ ) (Fig. 4).

In amniotic fluid there were similar gestational age-dependent changes in inositol concentrations $(r=0.688, p<0.001, n=45)$ as observed in fetal plasma although at day 18 the standard error was large (Fig. 3). 


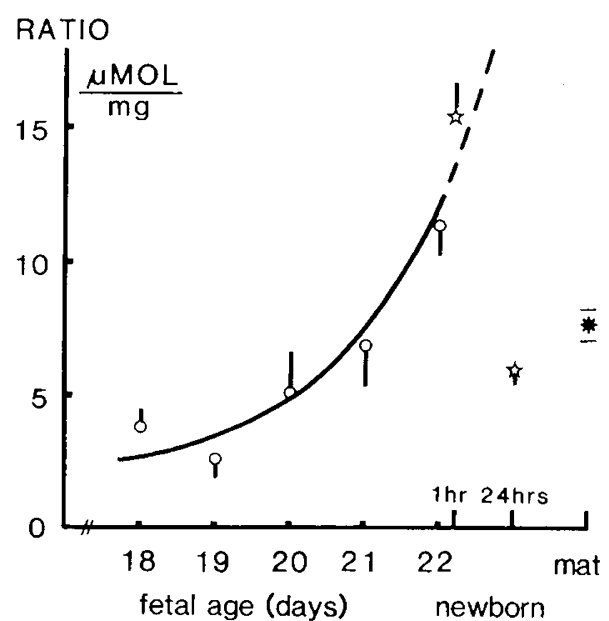

Fig. 2. Changes in the phospholipid/protein ratio of fetal surfactant $(O)$ and after birth (t) and the phospholipid/protein ratio of surfactant of the adult rat $(*)$. The ratio increases significantly from day 21 onward $(p<0.01)$ until birth and decreases significantly postnatally $(p<0.01)$. The results are the mean $\pm S E$ of five to 10 assays of fetal material, four and three assays of newborn surfactant and of $4 \mathrm{I}$ assays of adult rat surfactant.

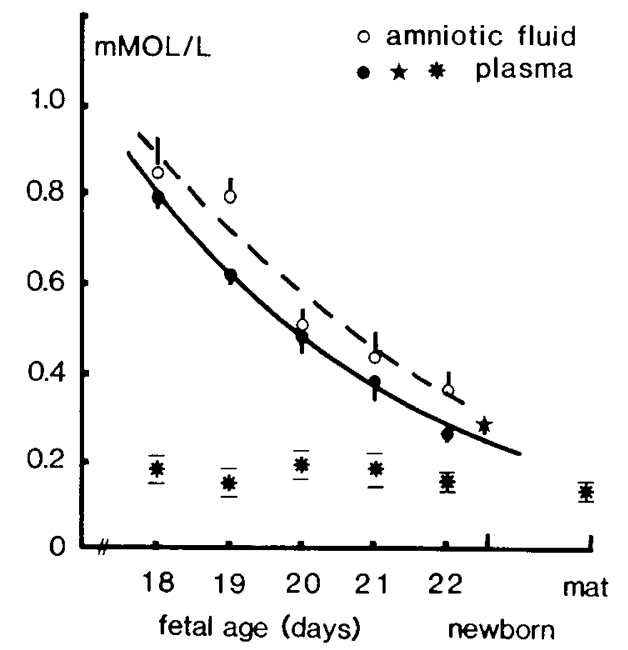

Fig. 3. The decrease of inositol concentration in plasma and amniotic fluid during gestation $(\bullet, O)$ and the level of plasma inositol in the adult rat during pregnancy (*). Inositol was estimated indirectly by fluorometry as described in "Materials and methods." The results are the mean \pm SE of three to nine assays of fetal plasma, five to nine assays of maternal plasma, and six to nine assays of amniotic fluid.

\section{DISCUSSION}

The composition of fetal lung surfactant is better documented for man $(3,14)$, rabbits $(15,16)$, and sheep $(17,18)$ than for the rat (19).

Fariday et al. (20) described the disaturated DSPC content of fetal rat lung lavages, whereas Adamson and King (21) estimated the change in total DSPC of fetal lung tissue. However, Young et al. (22) found that surfactant DSPC accounts for only $30 \%$ of the total amount of lung DSPC. In our study we determined both the change in composition and the increase in amount of fetal rat lung phospholipids and surfactant from the 18 th day onward. The significant amounts of PG in the so-called "surfactant" fraction of 18-day-old fetal rats (approximately $7 \mathrm{nmol} / \mathrm{g}$ lung) seems remarkable because the isolated fraction resembled otherwise that of total lung tissue in which PG is less than $1 \%$

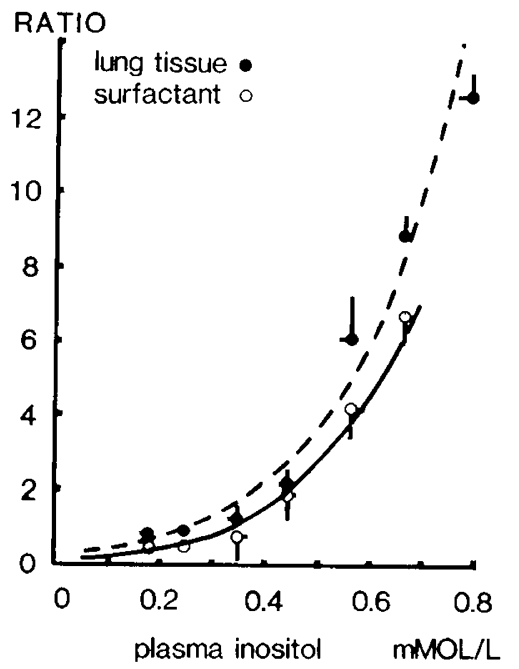

Fig. 4. Relationship between the fetal plasma inositol level and the $\mathrm{PI} / \mathrm{PG}$ ratio in lung tissue $(\bullet)$ or in surfactant $(\mathrm{O})$. Inositol was estimated by fluorometry as described in "Materials and methods." The PI/PG ratio was calculated after thin-layer chromatography and phosphorus estimation as described. The results of the PI/PG ratio and inositol concentration (classes $0.1 \mathrm{mM} /$ liter) are given as mean $\pm \mathrm{SE}$ of four to 11 combinations. The PI/PG ratios in lung tissue are significantly higher than those in surfactant material ( $p<0.01$, Sign test for paired samples).

before day 20. The surfactant fraction might be contaminated by mitochondrial PG or cardiolipin which runs in our system almost as fast as PG (23). Furthermore, because of the extremely small amounts of material, relatively large errors are introduced.

After two-dimensional thin-layer chromatography, we found that less than $15 \%$ of the PG of the 20-day surfactant and less than $3 \%$ of the PG of 22-day surfactant did not cochromatograph with a PG standard. These percentages of contamination of onedimensionally isolated PG agree with the results of the calculation assuming contamination of the surfactant fraction by "nonsurfactant" material as much as the 18-day material. Furthermore, electronmicroscopy of 21-day material showed that the peHet material of the surfactant fraction was not contaminated by other organelles. High speed centrifugation $(40,000 \times g)$ was, however, not effective enough to obtain a surfactant pellet of the 19-day material. If surfactant is present then, it might be present as vesicles which need higher g-forces for sedimentation (24).

The phospholipid/protein ratio of fetal rat surfactant appears to change and is at the end of gestation approximately the same as found for the surfactant of the fetal lamb (17) and the surfactant isolated from human amniotic fluids (14). The fetal surfactant phospholipid/protein ratios are higher than those found in the adults of various species $(25,30)$. The gestational age-dependent increase in this ratio in the fetal rat is probably the result of an increase in the phospholipid content of the lamellar body and could then be a measure of lamellar body maturation. The results of Magoon et al. (27) support this suggestion. They estimated the turnover-time of saturated phosphatidylcholine of two lamellar body fractions different in density and phospholipid/protein ratio and they suggest that the longer turnover-time that was found for lamellar bodies with the highest phospholipid/protein ratio results from their intracellular growth.

A high phospholipid/protein ratio of fetal surfactant might be important because larger amounts of surfactant phospholipids than in adults may be needed to overcome the postulated effects of a so-called "inhibitory protein" (28) which might pass the alveolar blood barrier during the immediate postnatal period.

In man, the changes in phospholipid profile, especially the decrease in percentage of PI and the increase in the percentage of $\mathrm{PG}$, correlates with a decreased risk for developing neonatal 
respiratory distress $(4,29)$. However, in diabetic patients fetal surfactant PG appear later in gestation than normally $(29,30)$. This may indicate that in such fetuses the gestational age-dependent decrease in the plasma inositol levels is delayed.

The changes in the composition of rat surfactant are similar to those in man whereas such changes do not occur in the surfactant of fetal rabbits or lambs. Our results also suggest that the PI/PG ratio in the surfactant decrease with the gestationalage-related decrease in fetal rat plasma inositol concentration. The possibility of a causal relationship is supported by the findings of Quirk et al. (32), who noticed that elevating the fetal plasma inositol levels in the rat resulted in higher PI/PG ratio of their lung tissue phospholipids. The fetal rat may therefore be a good model for studying factors which affect fetal lung maturation especially with respect to the synthesis of PI and PG.

Acknowledgments. The authors thank Dr. R. Otto-Verberne and $\mathrm{Mr}$. M. J. van Groeningen for the electron microscopy (Department of Anatomy), Dr. D. O. E. Gebhardt for his critical remarks, and Mrs. M. Van der Sanden for her assistance in preparing the manuscript.

\section{REFERENCES}

1. Farrell PM 1982 Lung Development: Biological and Clinical Perspectives, Vol I. Academic Press, New York, pp 223-238

2. Gluck L, Kulovich MV, Boree RC Jr, Brenner PH, Anderson GG, Spellacy WM 1971 Diagnosis of respiratory distress syndrome by amniocentesis. Am J Obstet Gynecol 109:440-445

3. Oulton M, Martin TR, Faulkner GT, Stinson D, Johston JP 1980 Developmental study of a lamellar body fraction isolated from human amniotic fluid. Pediatr Res 14:722-728

4. Hallman M, Kulovich MV, Kirkpatrick E, Sugerman RG, Gluck L 1976 Phosphatidylinositol (PI) and phosphatidylglycerol (PG) in amniotic fluid. Indices of lung maturity. Am J Obstet Gynecol 125:613-617

5. Hallman M 1981 Fetal development of surfactant: considerations of phosphatidylcholine, phosphatidylinositol and phosphatidylglycerol formation. Prog Resp Res 15:27-40

6. Hallman M, Epstein BL 1980 Role of myo-inositol in the synthesis of phosphatidylglycerol and phosphatidylinositol in the lung. Biochem Biophys Res Comm 92:1151-1159

7. Bleasdale JE, Maberry MC, Quirk JG 1982 Myo-inositol homeostasis in foetal rabbit lung. Biochem J 206:43-52

8. Beppu OA, Clements JA, Goerke J 1983 Phosphatidylglycerol deficient lung surfactant has normal properties. J Appl Physiol 55:496-502

9. Duck-Chong CJ 1978 The isolation of lamellar bodies and their membraneous content from rat lungs and human amniotic fluid. Life Sci 22:2025-2030

10. Bhagwanani SG, Fahmy D, Turnbull AC 1972 Quick determination of amniotic fluid lecithin concentration for prediction of neonatal respiratory distress. Lancet 2:66-67

11. Touchstone JC, Chen JC, Beaver KM 1980 Improved separation of phospholipids in thin layer chromatography. Lipids 15:61-63
12. Bradford M 1976 A rapid and sensitive method for the quantitation of microgram quantities of protein, utilizing the principle of protein-dye binding. Anal Biochem 72:248-254

13. Garcia Buñuel L, Garcia Buñuel VM 1964 Enzymatic determination of free myo-inositol in human cerebrospinal fluid and plasma. $\mathbf{J}$ Lab Clin Med 64:461-468

14. Hallman M, Merritt TA, Schneider H, Epstein BL, Mannino F, Edwards DK Gluck L 1983 Isolation of human surfactant from amniotic fluid and a pilot study of its efficacy in respiratory distress syndrome. Pediatrics 71:473-482

15. Hallman M. Gluck L 1980 Formation of acid phospholipids in rabbit lung during perinatal development. Pediatr Res 14:1250-1259

16. Longmuir KJ, Snyder JM, Mendelson CR, Johnston JM 1981 Phospholipid composition of lamellar bodies formed by fetal rabbit lung type II cells in organ culture. Arch Biochem Biophys 212:491-500

17. Egberts J, Clark C, Kodack L, Brumley G 1984 Intrauterine hypercarbia and lamb lung surfactant synthesis. Respir Physiol 57:213-223

18. Benson BJ, Kitterman JA, Clements JA, Mescher EJ, Tooley WH 1983 Changes in phospholipid composition of lung surfactant during development in the fetal lamb. Biochim Biophys Acta 753:83-88

19. Katyal SL, Estes LW, Lombardi B 1977 Method for the isolation of surfactant from homogenates and lavages of lung of adult, newborn and fetal rats. Lab Invest 36:585-592

20. Fariday EE, Thliveris $\mathbf{J}$, Morris GS 1981 Relationship between intra and extracellular DSPC in fetal and neonatal rats. Respir Physiol 45:55-66

21. Adamson IYR, King GM 1984 Sex differences in development of fetal rat lung: I. Autoradiographic and biochemical studies. Lab Invest 50:456-460

22. Young SL, Kremers SA, Apple JS, Crapo JD, Brumley G 1981 Rat lung surfactant kinetics: biochemical and morphometric correlation. J Appl Physiol 51:248-253

23. Spillman T, Cotton DB, Sherwood C, Bretaudiere JP 1984 Removal of a component interfering with phosphatidylglycerol estimation in the "Helena" system for amniotic fluid phospholipids. Clin Chem 30:737-740

24. Baritussio A, Bellina L, Carraro R, Rossi A, Enzi G, Magoon MW, Mussine I 1984 Heterogeneity of alveolar surfactant in the rabbit; composition, morphology and labelling of subfractions isolated by centrifugation of lung lavage. Eur J Clin Invest 14:24-29

25. Jobe A, Ikegami M, Sarton-Miller J, Barajas L 1980 Surfactant metabolism of the newborn lamb lungs studied in vivo. J Appl Physiol 49:1091-1098

26. Post M, Batenburg JJ, Schuurmans EAJM, Laros CD, van Golde LMG 1982 Lamellar bodies isolated from adult human lung tissue. Exp Lung Res 3:1728

27. Magoon MW, Wright JR, Baritussio A, Williams MC, Goerke J, Benson BJ, Hamilton RL, Clements JA 1983 Subfractionation of lung surfactant. Implication for metabolism and surface activity. Biochim Biophys Acta 750:1831

28. Ikegami M, Jobe A, Jacobs H, Lam R 1984 A protein from airway of premature lambs that inhibits surfactant function. J Appl Physiol 57:1134-1142

29. Haliman M, Feldman BH, Kirkpatrick E, Gluck L 1977 Absence of phosphatidylglycerol in respiratory distress syndrome in the newborn: study of the minor phospholipids. Pediatr Res 11:714-720

30. Cunningham MD, Desai NS, Thompson SA, Greene JM 1978 Amniotic fluid phosphatidylglycerol in diabetic pregnancies. Am J Obstet Gynecol 131:719724

31. Tsai MY, Shultz EK, Nelson JA 1984 Amniotic fluid phosphatidylglycerol in diabetic and control pregnant patients at different gestational lengths. Am $\mathbf{J}$ Obstet Gynecol 149:388-392

32. Quirk JG, Baumgarten B, Bleasdale JE 1984 Effect of myo-inositol on the glycerophospholipid composition of adult and fetal rat lung tissue. J Perinat Med 12:201-210 